\title{
A CONSTITUIÇÃO DO DISCURSO PEDAGÓGICO E SUAS IMPLICAÇÕES NA AULA DE LÍNGUA ESTRANGEIRA
}

Jakeline Aparecida SEMECHECHEN

Raquel Cristina Mendes de CARVALHO

Universidade Estadual do Centro-Oeste

Resumo: O presente artigo relata uma pesquisa etnográfica cujo propósito era investigar como uma professora organiza, estrutura e regula seu discurso na aula de Língua Estrangeira. Para conduzir este estudo, os dados foram coletados nas aulas de Inglês de uma escola particular, através das gravações das aulas em áudio, diário da professora e das notas de uma observadora. Os dados foram analisados à luz da teoria de Bernstein sobre o discurso pedagógico, registros regulativo e instrucional. Este estudo enfatiza que o discurso do professor é organizado para promover interação na aula (registro regulativo) e para promover insumo na língua estrangeira, mas principalmente que o uso da língua estrangeira em ambos registros (regulativo e instrucional) promove mais oportunidades para os aprendizes desenvolver a competência comunicativa na língua estrangeira, neste caso em Língua Inglesa.

Palavras-chave: discurso pedagógico; língua estrangeira; competência comunicativa

Abstract: The present article relates an ethnographically research that
has the purpose of investigate how a teacher organizes, structure and
regulates her discourse in foreign language class. In order to carry out
this study, data were collected in the English classes of a private school,
by means of tape recordings of classes, and field notes from the teacher
and from an observer. The data were analyzed through the lights of
Bernstein's pedagogic discourse, the regulative and instructional register.
Then, this study emphasizes that teacher's discourse is organized to
promote interaction in the class (the regulative register) and to promote
insumo in the foreign language (instructional register), but mainly that
use of the foreign language in both registers (regulative and instructional)
promote more opportunities to the learners develop the communicative
competence in the foreign language, in this case, in English Language. 
Keywords: pedagogic discourse; foreign language; communicative competence

\section{Introdução}

As aulas de Língua Estrangeira (LE) precisam englobar em sua prática cotidiana o ensino, a aprendizagem e o uso da LE devido à sua função social, uma vez que, segundo Magalhães (2002), a escola deve ser analisada enquanto agente cultural, a qual deve ter relação com a comunidade e com a sociedade. Sendo assim, as aulas necessitam ser analisadas sob a perspectiva social. Daí a relevância de uma abordagem de ensino de LE que vise o desenvolvimento da competência lingüística e social.

Nessa perspectiva, é importante ressaltar que são relações discursivas que medeiam, facilitam e organizam um contexto de ensino e aprendizagem de LE para que este seja constituído por práticas, ações e interações que oportunizem e possibilitem a aprendizagem contextualizada, significativa, cooperativa e construída para que o aluno, por conseguinte, adquira sua competência comunicativa na LE.

Neste processo, a prática discursiva do professor é preponderante, uma vez que, segundo Allright \& Bailey (1991), a fala é um dos maiores instrumentos de ensino e também de condução e regulação das situações para aprendizagem. Assim sendo, além de mediar a aprendizagem quanto às estruturas e função da língua, o professor com seu discurso coordena e é responsável para que as situações e interações tenham foco em tal perspectiva, pois o "discurso é o instrumento do educador em sua rotina de sala de aula." (GENTILI; ALENCAR, 2001 apud PINHEIRO, 2004, p.15).

Daí a relevância de uma abordagem de ensino de LE que reconheça e enfatize o discurso não só como meio para o insumo lingüístico, mas como facilitador das relações discursivas em sala de aula e, conseqüentemente, em situações interativas que a transcendam e constituam outros contextos nos quais se possam evidenciar alunos como sujeitos discursivos e competentes lingǘstica e comunicativamente na LE.

Nessa perspectiva, o presente estudo, com fundamentação em Bernstein (1996) sobre a estruturação e disposição do discurso pedagógico, procura evidenciar e analisar situações deste discurso, 
enfatizando-o enquanto regulativo e instrucional. Por meio desta análise busca-se investigar como a fala da professora é estruturada e organizada para conduzir as relações discursivas e as situações na aula de Língua Inglesa LI. Da mesma forma procura-se verificar como a professora se utiliza deste discurso para também constituir insumo na LI, contribuindo para a construção de um contexto favorável para o desenvolvimento da competência comunicativa, lingüística e social dos alunos.

Para o desenvolvimento desta pesquisa-ação (THIOLLENT 1996), foram gravadas em áudio oito aulas de Língua Inglesa na $1^{a}$. Série do Ensino Fundamental de uma escola particular de Guarapuava, das quais foram transcritas quatro aulas ministradas no período de 14 de fevereiro a 14 de março de 2006. Foram utilizadas, como procedimentos na coleta de dados, a descrição do contexto e de sua produção em diários de campo da professora e as notas de uma observadora.

Por fim, apresenta-se a análise desenvolvida na perspectiva da teoria do Discurso Pedagógico enquanto regulativo e instrucional (BERNSTEIN, 1996), através da triangulação dos dados levantados (RIGGENBACH, 1999), e na seqüência as considerações finais acerca do trabalho.

\section{Contexto e participantes da pesquisa}

A presente pesquisa-ação foi desenvolvida nas aulas de Língua Inglesa na $1^{\text {a }}$. Série do Ensino Fundamental de uma escola particular. Essa escola esta localizada no centro da cidade de Guarapuava atendendo também os bairros circunvizinhos com a oferta de Educação Infantil e Ensino Fundamental desde 1999.

Participou desta pesquisa a turma da $1^{\text {a }}$. Série do Ensino Fundamental, constituída por 11 alunos com sete anos de idade, sendo quatro meninas e sete meninos. Destes alunos aqui descritos com nomes fictícios, Eduardo, Cíntia e Tais estudam nessa escola desde o Jardim I (Pré 1), Pablo, Felipe, Ariel, a partir do Jardim II (Pré 2), Karina, Adriana, Caio e Henrique desde o Jardim III (Pré 3), tendo aulas de Língua Inglesa com a mesma professora em todos esses períodos em que estudaram nessa escola. Paulo começou este ano a estudar inglês, nessa escola. 
A professora de Língua Inglesa que teve seu discurso investigado atua com ensino da LI nessa instituição desde 2003, ministrando as aulas para Educação Infantil e Séries Iniciais do Ensino Fundamental. Sua formação é em Letras-Inglês e suas Literaturas (curso que está sendo concluído este ano na Universidade Estadual do CentroOeste). Também participou desta pesquisa, fazendo observações das aulas, a professora regente da turma, atuante na área de alfabetização desde 1992, formada no Magistério (Educação Infantil e Séries Iniciais do Ensino Fundamental), com Licenciatura em Geografia e pósgraduação em Metodologia de Ensino de Geografia.

Embora, a observadora não seja formada especificamente na área de ensino e aprendizagem de LE, tem conhecimento de como o trabalho é desenvolvido, uma vez que tem acompanhado o trabalho da professora de Língua Inglesa desde 2003. Além disso, para essa investigação a observadora e a pesquisadora debateram questões concernentes ao objetivo da pesquisa e teorizações que a respaldavam.

\section{Perspectiva teórica}

No âmbito de ensino e aprendizagem de Línguas Estrangeiras (LE) comumente são evidenciadas práticas nas quais os professores desenvolvem trabalhos que objetivam atender o desenvolvimento de estruturas gramaticais e de algumas noções situacionais de uso, não enfatizando assim um contexto para que o ensino agregue uma abordagem da língua enquanto sua função social. De acordo com Kramsch (1991 apud SARMENTO, 2004, p. 15):

os professores de lingua estrangeira ainda reconhecem como sua responsabilidade ensinar aos alunos apenas recursos lingüísticos para atuarem adequadamente em outra comunidade lingüistica. Não reconhecem que tem a obrigação de ensinar habilidades de socializaçãa.

Essa perspectiva de ensino de LE não atribui ao professor dupla função, ou seja, além de ensinar é preciso educar e socializar o aluno, mas refere-se a um trabalho integrado, no qual, segundo os PCNs de LE: 
a aprendizagem de LE deve garantir ao aluno o desenvolvimento da capacidade de agir no mundo por meio da palavra em Lingua Estrangeira nas várias habilidades comunicativas via Lingua Estrangeira. Essa construça passa pelo envolvimento do aluno com os processos sociais de criar significados por intermédio da utilização de uma Lingua Estrangeira. (BRASIL, 1998, p. 19)

Sendo assim, no processo de ensino e aprendizagem de LE, é necessário assumir a perspectiva de acordo com Hymes em que "competência lingüística deve necessariamente envolver competência social”. (ERICKSON; SHULTZ, 1981, apud SARMENTO, 2004, p. 12). Isto é, para o aluno ser competente lingüística e socialmente, ele precisa saber agir adequadamente por meio da LE em diferentes contextos e situações, podendo ser estes permeados por diferentes valores e ideologias.

É preciso, pois, transcender abordagens da LE que enfocam seu uso estrutural ou funcional somente em contextos futuros. É importante partir da realidade e necessidade do aluno, oportunizando assim um contexto de aprendizagem que não rotula nem descreve o que está sendo aprendido, mas que também faz seu uso mediante a realidade e necessidade do contexto em que se está inserido.

Nessa abordagem da LE relacionada com a sociedade e os diversos fatores que a constituem é importante enfatizá-la sob a perspectiva da teoria do Discurso Pedagógico de Bernstein (1996). Bernstein foi professor da cátedra de Sociologia de Educação, na Universidade de Londres onde realizou desde 1971 estudos e publicações sobre o papel do currículo e da pedagogia no processo de reprodução cultural, assim como também sobre suas teorizações e conceitos acerca do discurso e de identidades sociais.

Ademais, Bernstein (1996) enfatizou a importância da educação para a construção de uma sociedade democrática, uma vez que para ele, é a educação responsável pela produção e reprodução de injustiça social. Daí a necessidade de examinar o processo de ensino e aprendizagem no sistema formal de ensino. (SANTOS, 2003 apud CARVALHO, 2005).

Neste trabalho, será enfatizada a teoria do Discurso Pedagógico no que se refere ao contexto educacional formal, aos 
sistemas de ensino institucionalizados, sendo enfocadas questões referentes à comunicação e à linguagem. Bernstein (1996) ressalta que:

a comunicação pedagógica na escola, no jardim da infância, na família, é o condutor de relações de classe; o condutor de relações de gênero; o condutor de relações religiosas, de relações regionais. A comunicação pedagógica é o condutor para padrões de dominação externos a ela própria. (p. 234)

A escola, desta forma, não está desvinculada dos fatores externos a ela, e a comunicação e as relações que permeiam esse contexto advêm de paradigmas sociais, como classe, religião, etc.. Assim como a escola não está alheia ao contexto social que a circunda, a sociedade também é resultante das relações conduzidas no âmbito escolar. Caracteriza-se, assim, um processo cíclico de relações entre a sociedade e a escola, em que uma conduz e influi na outra.

Nessa perspectiva, Bernstein (1996, p. 250) propõe um dispositivo pedagógico que tem regras internas que regulam a comunicação pedagógica e a tornam possível, sendo tal dispositivo similar ao lingüístico que, para o teórico, se constitui em "um sistema de regras formais, as quais regem as distintas combinações que fazemos ao falar e escrever."

Contudo, tais dispositivos variam de acordo com o contexto e não são independentes de ideologias, por isso não são estáveis, coadunando-se com a concepção de que não se pode tratar "a linguagem, a cultura e o conhecimento como totalidades estanques e isoladas, e sim como conjuntos abertos e dinâmicos" (BRASIL, 2006, p. 110).

O dispositivo pedagógico fornece também a gramática intrínseca do discurso pedagógico através de regras distributivas, recontextualizadoras e de avaliação (BERNSTEIN, 1996). É importante ressaltar que Bernstein, ao propor o dispositivo como gramática do discurso pedagógico, não está formulando nenhuma regra, ele apenas analisa uma condição já existente nesse contexto e diante de suas evidências, nomeia tais processos.

Desta forma, quanto às regras distributivas, é importante considerar: 
os meios pelos quais se constrói uma relação entre poder, grupos sociais e formas de consciência [...]. Pode-se dizer que essas diferentes ordens, esses diferentes ordenamentos de significado, criam diferentes conbecimentos, diferentes práticas. (BERNSTEIN, 1996, p. 254)

Ou seja, em cada contexto social, seja em relação a classe, gênero ou religião, emergem diferentes práticas discursivas, com diferentes significados, característica que corrobora a concepção de uso da linguagem abordada nos PCNs de LE que:

quando alguém usa a linguagem o faz de algum lugar localizado na bistória, na cultura e na instituição, definido nas múltiplas marcas de sua identidade social e à luz de seus projetos políticos, valores e crenças. (BRASIL, 1998, p. 35)

Quanto à regra recontextualizadora é ressaltado que se trata "de um princípio recontextualizador que, seletivamente, apropria, recoloca, refocaliza e relaciona outros discursos, para constituir sua própria ordem e seus próprios ordenamentos". (BERNSTEIN, 1996, p.259). Considerando assim, o discurso pedagógico não tem um discurso próprio e é segundo Bernstein "um princípio para apropriar outros discursos e colocá-los numa relação mútua especial, com vistas a sua transmissão e aquisição seletivas.” (p.259). Então, a partir das regras distributivas que são os diversos discursos imbuídos na sociedade, a escola, o discurso pedagógico, através da recontextualização que faz dos vários discursos, apropria estes discursos, visando a seus objetivos educacionais.

Ainda nessa perspectiva, Bernstein (1996) salienta que a escola pode incluir, como parte de sua prática recontextualizadora, discursos da família, da comunidade, das relações no grupo de colegas do adquirente, para propósitos de controle social, a fim de tornar seu próprio discurso mais eficaz.

Uma vez que o discurso pedagógico também é constituído pelo que Bernstein (1996) conceitua como discurso instrucional e discurso regulativo,

chamaremos de discurso instrucional, o discurso que transmite as competências especializadas e sua mútua relação; chamaremos de discurso 
regulativo o que cria a ordem, a relação e a identidade especializadas. (p. 258)

Quanto a esses dois discursos constituintes do discurso pedagógico enquanto recontextualizador de outros discursos, é importante ressaltar que "o discurso regulativo é, ele próprio, a précondição para qualquer discurso pedagógico" (BERNSTEIN, 1996, p. 260).

Corroborando tal teorização no contexto da sala de aula de LE e em uma abordagem de ensino que seja constituída por princípios que visem a desenvolver a competência comunicativa, é pertinente ressaltar que, de acordo com Christie (1999), o discurso regulativo utiliza discursos apropriados além do espaço escolar e recoloca-os como discurso instrucional para propósitos especiais de ensino. Sendo assim, o professor de LE na prática de ensino faz uso de discursos relacionados a questões de valores, ideologias e outros ao construir o contexto para o ensino da LE.

Nesse processo de recolocação, o discurso instrucional é transformado, e sua introdução e seqüência são determinadas pela operação do discurso regulativo, ou seja, o uso que a professora faz de seu discurso, no qual procura implicar as questões de ordem social. Logo, essa recontextualização de outros discursos envolve agentes que têm a função de recontextualizar e organizar seus discursos, sendo que nas escolas os agentes são os professores (CHRISTIE, 1999).

Desta forma, é plausível aludir no discurso do professor de LE a possibilidade e a responsabilidade de recontextualizar discursos da sociedade para propiciar aos alunos um contexto para aprendizagem, que englobe tanto o insumo lingüístico condizente com habilidades e conteúdos específicos, quanto as interações e princípios que regulam relações sociais e o desenvolvimento de demais práticas para aquisição da competência comunicativa.

Daí a relevância de evidenciar e analisar como a professora investigada recontextualiza discursos, em seu discurso pedagógico, regulativo e instrucional, contribuindo para a construção de um contexto na sala a fim de desenvolver a competência comunicativa em Língua Inglesa (LI). 


\section{Análise dos dados}

Nesta análise procurou-se evidenciar e analisar situações do discurso pedagógico enfatizando-o enquanto regulativo e instrucional, na perspectiva de investigar como a fala da professora é estruturada e organizada para conduzir as relações discursivas e as situações na aula de LI, bem como fornecer insumo no ensino da Língua Estrangeira citada.

Primeiramente, é importante exemplificar o seu discurso pedagógico, destacando as situações em que este é regulativo ou instrucional. Bernstein (1996), ao ressaltar que o discurso pedagógico é imbuído por tais registros, está se referindo à prática discursiva do professor como um todo. Desta forma, o discurso pedagógico pode ser constituído por mais registros regulativos do que instrucionais, ou vice-versa. Todavia, de acordo com Bernstein (1996), não há como o discurso pedagógico ser destituído de um destes registros.

Faz-se necessário, nesta análise do discurso pedagógico, considerar os enunciados da professora, turnos de fala, para verificar os discursos regulativos e instrucionais, podendo ocorrer em diferentes momentos e com diferentes funções enquanto componentes do discurso pedagógico.

Diante das incidências discursivas da professora, evidenciadas nas transcrições das aulas, verifica-se que seu discurso pedagógico constituiu-se em 610 turnos de fala, na aula do dia 14 de fevereiro de 2006, sendo 200 regulativos e 410 instrucionais. $\mathrm{Na}$ aula do dia 21 de fevereiro, seu discurso constitui-se em 435 turnos, sendo 209 regulativos e 226 instrucionais. O discurso pedagógico da aula do dia 07 de março de 2006 foi composto por 366 turnos, 133 regulativos e 233 instrucionais. $\mathrm{Na}$ última aula analisada, o discurso pedagógico foi constituído por 381 turnos, sendo 120 regulativos e 260 instrucionais.

Partindo do enfoque da estruturação do discurso da professora enquanto regulativo e instrucional, buscou-se evidenciar e analisar como a professora organizou e fez uso de tais discursos. Sendo assim, através das transcrições das aulas e dos demais dados coletados, evidenciam-se as atuações discursivas e suas implicações nas aulas de LI.

$\mathrm{Na}$ constituição do discurso da professora enquanto regulativo, verificou-se o registro que corresponde ao que Bernstein 
(1996) destaca como condição para apropriar e conduzir outros discursos, caracterizando-se como regulador. Tal constatação do discurso regulativo enquanto condutor pode ser exemplificado através do seguinte relato no diário de campo da professora:

Sendo que também direcionei os relatos dos alunos nas atividades orais. (AULA 4, 07-03-2006).

Neste fragmento sobre sua própria prática discursiva a professora diz estabelecer direcionamentos nas situações discursivas em sala de aula. Sendo assim, através de seu discurso regulativo, ela conduz as situações discursivas para tornar possível prática do discurso instrucional.

Ainda sob essa perspectiva, pode-se verificar nas notas da observadora, o discurso regulativo enquanto princípio regulador, condutor das relações discursivas e uma pré-condição para outros discursos. (BERNSTEIN, 1996).

A professora procurou sempre contornar os assuntos que não tinham relação com a aula, ou trazendo para aula de alguma forma ou desviando daquele assunto sem desmerecer a participação da criança. (AULA 2, 14-02-2006).

Com relação a essa prática discursiva da professora enquanto regulativa verifica-se que esta não está destituída como afirma Bernstein (1996) de um princípio de ordem e valores morais e sociais. A professora ao conduzir a fala dos alunos para outros direcionamentos como relata a observadora, age com base nos princípios educacionais de seu meio social, considerando a participação e opinião do aluno.

Deste modo a professora recontextualizou outros discursos, do âmbito educativo e social com relação a regras, a valores, etc. a fim de tornar seu próprio discurso pedagógico mais eficiente.

Outro aspecto do discurso regulativo da professora é o uso que ela faz deste, para facilitar e conduzir as interações com as atividades da aula. Por exemplo, no enunciado seguinte a professora solicita atenção dos alunos para a proposta de atividade. 
$1099 T^{\prime}$ : Por favor, please, pay attention. A teacher está explicando. (AULA 2, 14-02-2006)

118 T: Pay attention. Look at the blackboard, now. (AULA 3, 21 02-2006)

A regulação discursiva da professora também é acentuada nas situações e contextos que requer cooperativismo, trabalho em conjunto para que os propósitos tanto de ensino, como sociais, sejam desenvolvidos.

741 T: Come on. Help bim.

742 Ariel: Help.

743 Paulo: Help.(AULA3,21-02-2006)

Nessa situação, emerge a necessidade de um aluno receber ajuda; diante da não manifestação dos colegas, a professora utiliza seu discurso, solicitando-a.

Também o discurso regulativo da professora é eminente nas questões referentes à ordem, ao respeito e à interação entre os alunos.

553 Pablo: O tia, o Eduardo só fica jogando coisas em mim.

554 T: Eduardo, mais uma vez.please.

555 Pablo: (incompreendido).

556 Eduardo: E eu não fiz nada pra ele.

557 T: Eduardinho, peça desculpas pra ele.

558 Eduardo: Desculpa.

559 T: Sorry.

560 Eduardo: Sorry. (AULA 3, 21-02-2006).

Desta forma, a professora intervém na relação dos alunos, no intuito de mediar o entendimento entre ambos, bem como enfatizar atitudes condizentes com estas situações. Sendo assim, a professora estrutura seu discurso para enfocar o respeito com os outros e o bom

\footnotetext{
${ }^{1} T$, corresponde a abreviação de teacher. Os alunos são citados com nomes fictícios. Entretanto, quando mais de um aluno fala ao mesmo tempo, é utilizado a abreviação $S t$ s, correspondendo à students.
} 
relacionamento enquanto atitude necessária, recontextualizando assim um discurso eminente nos princípios das interações sociais.

É importante ressaltar que as normas e valores, em sua prática discursiva, não se constituem somente nos enunciados que se referem aos alunos, mas também com relação a sua própria postura, validando assim ainda mais seu discurso regulativo com relação à necessidade de respeito.

410 T: Please, Paulo me alcance o rádio.

411 Sts: (falam ao mesmo tempo).

412 T: Consegue Paulo?

413 Sts: (falam ao mesmo tempo).

414 T: Thank you.(AULA 3, 21-02-2006).

Ademais, o discurso regulativo da professora, imbuído pelas questões de regras, valores morais e sociais, e enquanto condutor das relações discursivas e de outros discursos e, por conseguinte de situações, também pode ser exemplificado na transcrição do excerto:

606 T: Mas não na desk né. Aonde que épra desenhar, aonde que é pra usar o pencil. É na desk da classroom (incompreendido).

607 Felipe: (incompreendido)

608 Sts: Não.

609 T: Não. É no notebook. (AULA 2, 14-02-2006)

Nesse fragmento verifica-se que a professora utilizando o discurso regulativo, conduz a situação para que o aluno não continue riscando a carteira na sala de aula. Sendo assim, além do favorecimento para a sala de aula no dado momento, ou seja, o aluno ter parado de riscar a carteira, esse discurso da professora, provavelmente pode ter influência em outros contextos sociais do aluno, caracterizando como sugere Bernstein (1996) a relação da escola com a sociedade.

Partindo da abordagem do discurso regulativo da professora convém destacar também evidências do discurso instrucional em seu discurso pedagógico, sendo que este para Bernstein (1996), trata-se de falas que se referem ao ensino de conteúdos e atividades específicas. Por exemplo: 
383 T: Então, a teacher vai dar um cartãozinho pra cada um de vocês. E vocês vão olhar pro amiguinho. E vão. Não pode mostrar pro amiguinho. Então vocếs vão pegar o cartão com o objeto da escola. Então, aî você vai perguntar pro amiguinho é "what is this?" é o que que é isso? Ai, o amiguinho vai responder "This is a pencil". Ai, se o amiguinho acertou, você diryes.

384 Adriana: Se ele não acertou. (AULA 3, 21 - 02-2006).

Nesta situação discursiva instrucional a professora está trabalhando determinado conteúdo (materiais escolares) e, de forma específica, explica a atividade com relação à sua função e ao conteúdo que precisa ser desenvolvido.

Ainda neste enfoque do discurso instrucional, também este pode ser exemplificado em situações discursivas destinadas a sanar dúvidas sobre o conteúdo e atividades explicadas, bem como nos casos de correções.

814 T: Write your name.

815 Sts: What's your name?

816 T: Não é what's your name? É write your name.

817 Sts: Write your name. (AULA 2, 14-02- 2006).

Em tal situação, diante da não compreensão do aluno sobre o conteúdo proposto, a professora explica novamente e corrige enfatizando a diferenciação entre o que realmente se objetivava e o que o aluno tinha compreendido, caracterizando assim o discurso instrucional.

Também constituindo o discurso pedagógico enquanto instrucional no ensino de LE, neste caso, particularmente de LI, podese exemplificar este no ensino específico de pronúncias, condição esta verificada no excerto seguinte:

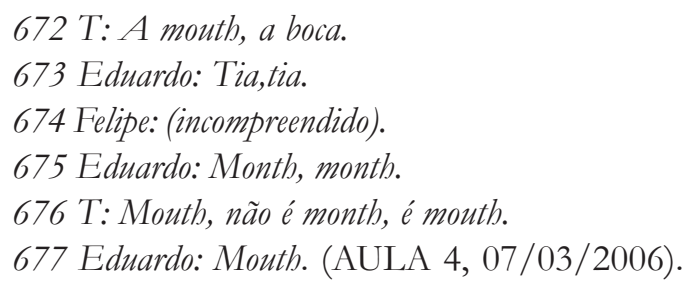


A professora nesta situação salienta a distinção entre as pronúncias e significados de mouth e month, correspondendo assim também ao que Bernstein (1996) ressalta como discurso sistematizado com intenção direta de ensino.

Além disso, nesse discurso instrucional da professora, também é evidenciado unidades gramaticais da LI, cabendo ressaltar que esta abordagem se dá enquanto uso e função, e não meramente pela estrutura.

180 T: Happy. She is happy. Ele se ela estivesse. E se fosse um boy. Um menino Pablo? Como que nós falaríamos para o boy, pro menino? 181 Pablo: She is happy.

182 T: She, she!

183 Sts: (risos).

184 T: Ou be is.

185 Pablo: He is happy. (AULA 4, 07-03-2006).

Neste contexto, a professora organiza seu discurso instrucional para abordar os pronomes pessoais a partir da sua função e uso.

Outro aspecto que instrucionaliza o discurso da professora, pode ser exemplificado quando esta solicita que os alunos utilizem em seu discurso não só regras de socialização, mas também formas de uso da LI.

1133 Ariel: Fazendo o favor teacher, dá pra ir no banbeiro.

1134 T: Ai, mais tem outra palavrinha como que pode ser.

1135 Cintia: (incompreendido).

1136 T: Excuse pode ser também.

1137 Ariel: Teacher dá pra ir no banbeiro.

1138 Henrique: Com licença.

1139 T: Ou pode falar assim.

1140 Ariel: Excuse me.

1141 T: Yes, ok, good. Ou pode falar May I go to the Toilet?

1142 Ariel: May I go to the Toilet? (AULA 2, 14-02-2006).

É importante ressaltar que esta situação poderia ser tomada enquanto regulativa, no entanto não o é, pois, embora a professora 
esteja se referindo a uma regra social da escola, ela diz ao aluno, como ele deve falar na LI. Sendo assim, a partir do momento que a professora ensinou, e não apenas fez uso de determinada norma de conduta, já está ensinando, ou seja, utilizando seu discurso instrucional.

Também com relação a essa instrucionalização do discurso da professora se referindo a questões de normas e regras sociais, é possível afirmar a ocorrência de uma situação de ensino, não apenas de condução e uso, fator verificado em seu diário de campo.

Emergiu também a necessidade de reenfatizar algumas (polites words). (AULA 3, 21-02-2006).

Nesta nota, a professora ao referir-se a uma reenfatização, deixa implícito que não apenas fez uso de tais conteúdos, mas que também os abordou em teor de ensino.

A partir do enfoque do discurso da professora enquanto regulativo e instrucional e seus usos e funções na aula de LI, é importante tecer algumas considerações sobre suas implicações para o desenvolvimento da competência comunicativa, lingüística e social nos alunos.

Primeiramente, é necessário destacar o constante uso da LI no discurso pedagógico, tanto no regulativo, quanto no instrucional. $\mathrm{O}$ fato de a professora utilizar a LI em seu discurso regulativo e não apenas no discurso instrucional (ensino de conteúdos e funções específicas), faz com que sua fala, além de organizar e conduzir as relações e situações na aula para que o contexto seja pertinente à aprendizagem, seja por si só uma significação da LI que tem uma função contextualizada. Da mesma forma, mediante as questões de ordem, regras e valores sociais que dão envolvimento e aproximação, o aluno se apropria da significação social do ensino e aprendizagem da LI.

Esse uso da LI não somente no discurso instrucional, foi evidenciado no decorrer das análises dos enunciados da professora $\mathrm{e}$ também pode ser exemplificado através das notas da observadora.

No início da aula a professora adentrou na sala se comunicando em inglês e os alunos responderam em inglês. (AULA 2, 14-02-2006). 
A partir desta citação da observadora, verifica-se que, ao iniciar a aula em LI, a professora está fazendo uso de seu discurso regulativo, e pelo fato de os alunos corresponderem a essa ação discursiva, pode-se supor que eles estejam habituados a esse discurso, internalizado em práticas anteriores.

Ademais, pode-se verificar através do seguinte excerto, que tais relatos de início de aula corroboram com a transcrição das aulas:

010 T: Hel. Excuse me.

011 Ariel: Não come in.

012 T: Ai. Sorry a teacher esqueceu. (volta e bate na porta).

013 Sts: Come in. Come in.

014 T: Excuse me.

015 Sts: How are you?

016 T: Fine, thanks. How are you?

017 Sts: Fine, thanks. (AULA 3, 21-02-2006).

Sendo assim, no contexto da sala de aula, as saudações têm significação na perspectiva social, elas são utilizadas e validadas no dia -a -dia. Partindo também desse fragmento de aula em que a professora pede licença aos alunos, nota-se que o seu discurso é constituído pelas normas e valores que ela procura conduzir e fazer com que sejam utilizados nas interações em sala de aula, como se verifica nas suas notas de aula.

É importante ressaltar que é constante o uso de estruturas já trabalhadas e também de (polite words) no decorrer de toda a aula. (AULA 4, 0703-2006).

O discurso da professora não implica somente em regulações das relações e do uso de práticas discursivas pelos alunos na sala de aula, uma vez que a professora não estabelece simplesmente normas e valores discursivos a serem utilizados pelos alunos, mas faz usos dos mesmos, influenciando as práticas sócio-discursivas na sala de aula e, conseqüentemente, em outros contextos. Isso também pode ser observado no turno da professora dirigido ao aluno: 
1174 T: Na primeira linha (incompreendido), Pablo, please. Pablo sit

down. Calm down, please. Primeira linha (interrupcão).

1175 Ariel: Sit down, please. (AULA 2, 14-02-2006).

Entretanto, embora sejam contínuas as práticas discursivas que imbricam a LI na perspectiva funcional e de significação social, muitas vezes podem não ser encontradas em alguns discursos na sala de aula, o que se verifica no fragmento seguinte:

055 Caio: $A$ u, au.

056 T: Caio, please.

057Felipe: Cale a boca (fala para Caio). (AULA 3, 21-02-2006).

Nessa situação, embora a professora tenha organizado seu discurso adequadamente enquanto regulativo (normas e valores), o aluno não correspondeu, agindo discursivamente de uma forma contrária.

Essa constatação acentua a relevância do discurso pedagógico e sua necessidade de ser recontextualizado sob a perspectiva social (BERNSTEIN, 1996), uma vez que, com desenvolvimento e organização contínuos desse discurso, tais situações tendem a diminuir, considerando que o aluno tem maior contato com esse discurso, passando então, a utilizar os valores e regras nele presentes.

Desta forma, a estruturação do discurso da professora enquanto regulativo e instrucional, tendo como finalidade a organização da sala de aula, constrói um contexto favorável para o processo de ensino e a aprendizagem, pode transcender, na perspectiva de Hall e Walsh (2002), a possibilidade de construção de modelos e normas para participação nas atividades em sala de aula, o que pode influir na participação de futuros eventos educacionais e demais grupos sociais.

Concomitantemente ao uso da LI no discurso pedagógico como um todo, não somente no instrucional, é possível verificar que a aula de LI assume a perspectiva de significação social, pois o ensino da língua passa a ser imbuído tanto pela abordagem da gramática (considerando que toda língua é constituída por uma gramática) quanto por sua função e significação na sociedade.

Assim, ao adotar tal postura pedagógica discursiva, a professora não está somente organizando a aula a fim de que seja 
possível o desenvolvimento das atividades (discurso regulativo), mas também está oportunizando a aquisição da competência comunicativa, lingüística e social em LI.

\section{Conclusão}

Partindo da análise realizada acerca de como a professora de LI utiliza seu discurso, para a construção de um contexto na sala de aula que seja favorável à aquisição da competência comunicativa pelos alunos, evidenciou-se que é através do uso constante e equilibrado dos registros regulativo e instrucional na LI, que são construídas as situações mais concernentes para o desenvolvimento da competência lingüística e social, ou seja, da competência comunicativa.

Pode-se verificar que a professora de LI, ao conduzir sua aula com relações às atividades e interações, estruturou e organizou seu discurso a fim de que este atendesse às necessidades de ordem lingüística e social dos alunos. Entretanto, tal prática não deve ser relacionada ao ensino de valores e normas de conduta, mas sim, à construção de um contexto que trabalhe com tais questões, diante das situações que emergem na sala de aula, que tem relação com o propósito de ensino e, sobretudo, com a função e significação social da língua.

Sendo assim, faz-se necessário considerar o propósito do ensino da LE como possibilidade de o aluno aumentar sua percepção enquanto ser humano e cidadão também através de uma LE (PCNs, 1998), pois “o valor educacional da aprendizagem de uma língua estrangeira vai muito além de meramente capacitar o aprendiz a usar uma determinada língua estrangeira para fins comunicativos". (DIRETRIZES CURRICULARES, 2006, p.92).

Enfim, é importante então, repensar o discurso do professor de LE não somente ao que se refere ao ensino da língua enquanto meio para comunicação, mas principalmente com relação ao seu uso, função e significação social, utilizando o contexto desse processo de ensino e aprendizagem para a construção de uma sociedade mais justa e democrática. 


\section{Referências}

ALLRIGHT, Dica; BAILEY, Kathleen M. Focus on the Language Classroom: an introduction to classroom research for language teachers. Cambridge: CUP, 1991.

BERNSTEIN, Basil. A estruturação do discurso pedagógico: classe, códigos e controle. Trad. Tomaz Tadeu da Silva e Luis Fernando Gonçalves Pereira. Petrópolis: Vozes, 1996. v. IV.

BRASIL. Ministério da Educação e do Desporto. Secretaria de Educação Fundamental. Orientações Curriculares Nacionais (Ensino Médio): língua estrangeira/ Brasília: MEC/SEF, 2006.

Secretaria de Educação Fundamental. Parâmetros curriculares nacionais: terceiro e quarto ciclos do ensino fundamental: língua estrangeira. Secretaria de Educação Fundamental. Brasília: MEC/SEF, 1998.

CARVALHO, Raquel Cristina Mendes de. A teacher's discourse in EFL classes for very young learners: investigating mood choices and register. Dissertação de Mestrado. UNICENTRO/UFSC, 2005.

CHRISTIE, Francis. Pedagogy and the Shaping of consciousness: linguistic and social process. London: Continuum, 1999.

HALL, Joan Kelly; WALSH, Martins. Teacher-student interaction and language learning. USA: Annual Review of Applied Linguistics, Vol.22. 2002.

MAGALHÃES, Maria Cecilia. O professor de línguas como pesquisador de sua ação: a pesquisa colaborativa. In GIMENEZ, Telma (Org). Trajetórias na formação de professores de língua. Londrina: UEL, 2002.

OLIVEIRA. Cristina. O discurso dos alunos e do professor: um vínculo comunicativo entre a comunidade e a escola. Revista Virtual de Estudos da Linguagem - REVEL, a. 3, n. 4, 2005. Disponível em: <http:// www.revelhp.cjb.net> . Acesso em: 20 de fevereiro de 2006. 
PINHEIRO, Sonia Regina Potenza Guimarães. Discurso Regulatório e Instrucional: a construção da não violência numa Atividade de Ensino sob a Perspectiva da Teoria da Atividade. 2004. 110f. Dissertação (Mestrado em Lingǘstica Aplicada e Estudos da Linguagem) Universidade Estadual de Campinas, Campinas.

RIGGENBACH, Heidi. Discourse analysis in the language classroom. United States of America: University of Michigan Press, 1999.

SARMENTO, Simone. Ensino de Cultura na aula de língua estrangeira. Revista Virtual de Estudos da Linguagem - REVEL, a. 2, n. 2, 2004. Disponível em: <http://www.revelhp.cjb.net>. Acesso em: 16 de março de 2006.

THIOLLENT, Michel. Metodologia da pesquisa-ação. São Paulo: Cortez, 1994. 